\title{
A EDUCAÇÃO PÚBLICA NO BRASIL NO SÉCULO XX: CONSIDERAÇÕES À LUZ DA FORMAÇÃO DOS GRUPOS ESCOLARES E DO MANIFESTO DOS PIONEIROS DA EDUCAÇÃO NOVA
}

\author{
LA ENSEÑANZA PÚBLICA DE BRASIL EN EL SIGLO XX: CONSIDERACIONES A \\ LA LUZ DE LA FORMACIÓN DE LOS GRUPOS ESCOLARES Y DEL \\ MANIFIESTO DE LOS PIONEROS DE LA EDUCACIÓN NUEVA
}

\section{PUBLIC EDUCATION IN BRAZIL IN THE 2OTH CENTURY: CONSIDERATIONS IN THE LIGHT OF THE TRAINING OF THE SCHOOL GROUPS AND THE MANIFESTO OF THE PIONEERS OF NEW EDUCATION}

\author{
Rebeca Pizza Pancotte DARIUS ${ }^{1}$ \\ Fábio Augusto DARIUS ${ }^{2}$
}

RESUMO: O ensino público no Brasil é resultado de inúmeras influências e tentativas de adequações. Neste artigo, o foco será o século XX, período de grande desenvolvimento científico e tecnológico e de expansão da educação. O método utilizado neste estudo foi bibliográfico, onde buscou-se discutir o legado educacional do século XX, a formação dos Grupos Escolares e o Manifesto dos Pioneiros da Educação Nova. São elementos necessários para a compreensão de como a educação no Brasil foi produzida neste período.

PALAVRAS-CHAVE: Legado educacional. Século XX. Grupos escolares. Manifesto dos pioneiros da educação nova.

RESUMEN: La enseñanza pública de Brasil es el resultado de innumerables influencias e intentos de adaptación. En este artículo, el foco estará centrado en el siglo XX; período de gran desarrollo científico, tecnológico y de expansión de la educación. El método utilizado en este estudio fue bibliográfico, con el cual se buscó discutir el legado educacional del siglo XX: La formación de los Grupos Escolares y el Manifiesto de los Pioneros de la Nueva Educación. Esos elementos son necesarios para la comprensión de cómo la educación en Brasil fue desarrollada en este período.

PALABRAS CLAVE: Legado educacional. Siglo XX. Grupos escolares. Manifiesto de los pioneros de la nueva educación.

\footnotetext{
${ }^{1}$ Centro Universitário Adventista de São Paulo (UNASP), Engenheiro Coelho - SP - Brasil. Pedagoga e Mestra em Educação (UEM). Coordenadora do Curso de Pedagogia e professora no ORCID: <http://orcid.org/0000-0001-7652-5450>. E-mail: rebeca.darius@ucb.org.br

${ }^{2}$ Centro Universitário Adventista de São Paulo (UNASP), Engenheiro Coelho - SP - Brasil. Professor e Pesquisador. Doutor em Teologia. ORCID: <https://orcid.org/0000-0001-6877-940X>. E-mail: fabio.darius@unasp.org.br
} 
ABSTRACT: Public education in Brazil is the result of innumerable influences and modifications. In this article, the focus will be the 20th century, period of great scientific and technological development and expansion of education. The method used in this study was a bibliographical one in which the aim was to discuss the educational legacy of the twentieth century, the formation of the School Groups and the Manifesto of the New Education Pioneers. These are necessary elements for understanding how education in Brazil was produced in this period.

KEYWORDS: Educational legacy. 20th century. School groups. Manifesto of the pioneers of new education.

\section{Introdução}

O século XX pode ser considerado um período importante para a história da escola pública no Brasil, devido às relevantes transformações pelas quais ela passou. É necessário considerar o contexto histórico do país para assim compreender como se deu a produção da educação para o povo. Entre alguns fatores determinantes, pode-se mencionar o início da República - final do século XIX em diante, a crescente industrialização no país, a expansão das cidades e a influência do modelo norte-americano de educação, conhecido como escolanovista.

De acordo com Cambi (1999, p. 509), o século XX foi "dramático, conflituoso, radicalmente inovador em cada aspecto da vida social: em economia, em política, nos comportamentos, na cultura". Ele afirma também que mudanças no modo de compreender as ciências influenciaram a educação, contribuindo para modificações na sociedade como um todo. Essas mudanças dizem respeito sobretudo ao modo de compreender a infância, dando ênfase a um ativismo nos ideários educacionais libertários. Como fundamento dessa nova consciência educacional estavam as descobertas da psicologia e os movimentos de emancipação das massas populares.

"No século XX, a escola sofre processos de profunda e radical transformação. Abre-se às massas. Nutre-se de ideologia. Afirma-se como cada vez mais central na sociedade" (CAMBI, 1999, p. 512). Ressalte-se que alguns pensadores da época almejavam que o Brasil alcançasse o nível de desenvolvimento dos outros países considerados desenvolvidos, especialmente os europeus. Para tanto, acreditavam que o modelo educacional também deveria ser copiado, uma vez que pela educação viria o desenvolvimento da nação. Assim, "a escola se impôs como instituição-chave da sociedade democrática" (CAMBI, 1999, p. 513). 
Neste texto, serão abordados alguns temas. Iniciar-se-á pelo legado educacional do século $\mathrm{XX}$, onde serão explanadas algumas considerações importantes que esse período histórico nos legou em termos de educação. Em seguida, será trabalhada a formação dos Grupos Escolares no Brasil do século XX, explicitando a transformação que houve no ensino primário em decorrência deles. Por fim, alguns elementos para compreensão do Movimento Escolanovista e o Manifesto dos Pioneiros da Educação Nova serão abordados.

\section{O legado educacional do século XX: apontamentos históricos}

De acordo com Saviani (2004), o século XX pode ser destacado como um período histórico de significativas conquistas técnicas e tecnológicas. Paradoxalmente ou não, é o século onde mais foi desprezada a vida humana, precisamente por conta dessas conquistas. Enquanto o desenvolvimento alcançou parcelas privilegiadas da população, melhorando seu modo de vida, também foi o período em que parcela considerável da humanidade passou por grandes opressões, ficando desapossada das conquistas que o desenvolvimento possibilitou.

O século XX foi realmente o século do "homem novo", mas este correspondeu cada vez mais àquele homem-massa, cuja fisionomia foi criticamente traçada por Ortega y Gasset, sublinhando suas estruturas, mas também seus custos (a perda da interioridade, o esquecimento do passado) e riscos (a rebeldia, o embrutecimento) (FRANCO, 1999, p. 511).

As aspirações decorrentes da implantação da República entendiam a educação como sendo a redentora para todos os males, cuja ideia ainda permanece no patamar utópico da democratização do conhecimento. Predominava o pensamento de que a educação seria responsável pelo desenvolvimento da sociedade democrática, incorporando um ideal educativo libertário (FRANCO, 1999). No entanto, o acesso à educação como cultura e conhecimento para todos, sobretudo no Ensino Superior, é realidade apenas para 14\% dos brasileiros. (CANCIAN, 2016)

O sistema escolar não é capaz de superar as diferenças entre as classes sociais, nem tampouco diminuir as diferenças entre riqueza e pobreza, sendo esta uma consequência do modo capitalista de produção. "O projeto pedagógico que deveria ser o sonho possível se mantém nos mesmos patamares dos últimos duzentos anos [...]” (Saviani, 2004, p. 2). 
No final do século XIX os republicanos anunciavam que se concretizaria o projeto de escola pública, obrigatória, gratuita, democrática e laica, cuja função seria a de corrigir as desigualdades sociais. O século XX herdou essa crença do poder da escola. Porém, o sistema educacional ainda não estava alicerçado, e se considerar a voracidade do capitalismo e a desigualdade decorrente deste, é possível perceber que não houve na história tantas pessoas à margem do desenvolvimento e vítimas desse sistema, num período de acelerado desenvolvimento tecnológico, científico, entre outros.

De acordo com Saviani (2004), as transformações mais acirradas que o Brasil teve em termos econômico, social, político, cultural, educacional se deram nas últimas duas décadas do século XIX. Saviani propõe uma divisão de períodos para explicar a história da escola pública no Brasil, sendo a $1^{\mathrm{a}}$ etapa correspondendo às seguintes fases: 1549-1759 escola pública religiosa (jesuítica); 1759-1827 - aulas régias (reforma pombalina); 18271890 - tentativas de organizar a educação sob o domínio do Estado.

Segundo Saviani (2004), em 1890 iniciou-se uma nova etapa, por meio da implantação dos Grupos Escolares, sendo este um marco da origem da escola pública no Brasil. Esta etapa está dividida em três períodos: 1) 1890-1931: corresponde ao momento em que houve implantação gradativa das escolas primárias nos estados brasileiros e a formação dos professores pelas escolas normais; 2) 1931-1961: período de regulamentação das escolas superiores, secundárias e primárias e, 3) 1961-1996: criação da primeira lei de Diretrizes e Bases (4.024/96) e da atual (9.394/96). Assim, Saviani aborda essa nova periodização traçando um roteiro da educação escolar brasileira no século $\mathrm{XX}$, considerando que esta deixou um legado perceptivelmente dialético. Como legado positivo tem-se uma ampla estrutura que envolveu um número maior da população do que a que anteriormente tinha acesso à escola, o desenvolvimento dos cursos de pós-graduação, a criação do Ministério da Educação e Saúde em 1930 (Vidal, 2006). Como legado negativo tem-se a baixa qualidade da educação, pois o fato de ter se expandido não garantiu alto padrão do ensino. Outro legado negativo foi a ausência de um sistema unificado de ensino para o país e também um grande número de analfabetos.

Pode-se dizer que a formação dos Grupos Escolares foi determinante para a história do ensino primário e a transformação dessas instituições educativas em escolas de $1^{\circ}$ grau a partir de 1970. Quanto ao currículo presente nas escolas até pelo menos a metade do século XX, predominou o programa de natureza enciclopédica, adotado no final do séc. XIX. 


\section{Os grupos escolares no Brasil}

De acordo com Vidal (2006), a presença dos Grupos Escolares na história da educação brasileira é significativa no período da República. Foram criados primeiramente em São Paulo e no Rio de Janeiro, no final do século XIX. Cerca de duas décadas após sua criação, se expandiu para outros estados brasileiros. Podemos dizer que eles fizeram parte do projeto educacional republicano e o intuito é que servissem de modelo para o restante do país (AMORIM, 2015).

Os Grupos Escolares centralizavam num único prédio as antigas escolas isoladas, organizando o ensino em salas seriadas e sequenciais sob a autoridade do professor. Nesse momento passa a existir o diretor, e uma nova hierarquia se configura na escola pública (VIDAL, 2006). Passa a haver também uma preocupação com a formação dos professores primários, uma vez que em sua maioria eram leigos; para tender tal demanda foi criada a Escola Normal em 1908 (AMORIM, 2015).

Os grupos escolares correspondiam a uma modalidade escolar que possuía métodos inovadores, avançados, modernos para o ensino primário que se contrapunham aos métodos ultrapassados utilizados pelas escolas de primeiras letras do período imperial. Portanto, essa escola republicana tinha como objetivo primordial agrupar em um só prédio e sob uma única direção todas as escolas isoladas de uma determinada localidade de acordo com o crescimento da população escolar (AMORIM, 2015, p. 211).

Para Souza e Filho (2006), os Grupos Escolares trouxeram relevante transformação no ensino primário no Brasil. A partir deles, houve a constituição de um espaço próprio para o funcionamento da escola pública, deixando de funcionar na residência dos professores para funcionar em prédios específicos. Assim, o Estado passa a ser responsável pela construção dos prédios escolares.

As matrículas nos Grupos Escolares eram para crianças de 7 a 12 anos, cuja frequência passa ser obrigatória. Esse movimento embasou a ideia de idade/série correspondente, o que motivou a criação de campanhas para resolver problemas relacionados à defasagem série/idade decorrentes da evasão e da repetência, como as campanhas de alfabetização (VIDAL, 2006).

De acordo com a autora acima citada, entre 1975-1999, o número de alunos matriculados cresceu aceleradamente, de 19,5 milhões para 36 milhões. Porém, o número de analfabetos era grande e um número considerável de crianças ainda estava fora da 
escola. O aumento da população urbana era um dado importante para explicar o índice crescente de analfabetismo, mesmo diante do fato do número de matriculas também ser crescente.

O alcance dos Grupos Escolares a toda população em idade escolar não foi possível devido a alguns fatores relevantes: os altos cultos para criação dos prédios escolares, as dificuldades de manutenção dos mesmos e a resistência de alguns grupos da sociedade que se incomodaram com o fato das crianças ficarem muitas horas sob a autoridade da escola, afastadas do lar e do trabalho produtivo.

Os Grupos Escolares fundaram uma representação de ensino primário que não apenas regulou o comportamento, reencenado cotidianamente, de professores e alunos no interior das instituições escolares, como disseminou valores e normas sociais (e educacionais) (Vidal, 2006, p. 9).

Para Souza e Filho (2006), os Grupos Escolares formaram uma modalidade de escola primária mais complexa, que marcou o século XX. "Dessa maneira, a história dos grupos se confunde com a história do ensino primário e está no centro do processo de institucionalização da escola pública” (p.25). Neste sentido, os Grupos Escolares tiveram grande importância na constituição da escola primária brasileira, reordenando o tempo e o espaço escolar, ampliando o currículo por meio de disciplinas de caráter enciclopédico.

$\mathrm{Na}$ análise de Vidal (2006), concomitantemente às mudanças educacionais em virtude dos Grupos Escolares, também existem as reformas da instrução pública influenciadas pelo movimento da Escola Nova, sobretudo entre 1920 e 1940. Esse movimento apresentava maneiras diferentes de se conceber as práticas e os saberes escolares por meio dos métodos de projetos e centros de interesse.

Assim sendo, o modelo de Grupo Escolar foi espalhado por toda a nação e deixou como legado do século XX a sistematização dele no que se concebe à primeira fase do ensino fundamental atualmente. De acordo com Saviani (2008), o legado positivo da implantação dos grupos escolares foi o maior rendimento das classes devido à formação das mesmas com alunos do mesmo nível de aprendizagem, e o legado negativo foi que os padrões de exigência escolar acarretaram no excessivo número de repetentes nas primeiras séries. Surgem então reformas para enfrentar o problema do analfabetismo.

\section{O manifesto dos pioneiros da Educação Nova e a sua influência nas mudanças educacionais no século XX no Brasil}


De acordo com Silva (2008), intelectuais brasileiros sofreram influência do movimento que afetou todo o mundo ocidental, denominado escolanovista, cujo idealizador, nos Estados Unidos, é o pensador John Dewey, valendo ressaltar que na Europa esse movimento também foi muito forte. No Manifesto dos Pioneiros da Educação Nova estavam contidos os princípios do Movimento da Escola Nova, "uma mistura da rigidez educacional européia com um sistema forte, com o pragmatismo norte-americano, centrado na ciência e no desenvolvimento econômico e social” (Silva, 2008, p. 3).

Assim sendo, em 1932, um grupo de intelectuais produziram o referido documento, citado acima, para alcançar o povo e o governo. Tratava-se da luta de um grupo de intelectuais em prol da escola pública objetivando uma revalorização da educação. Idealizava a reforma social por meio da reforma educacional.

Como instrumento político, o Manifesto dos Pioneiros "expressa a posição do grupo de educadores que se aglutinou na década de 1920 e que vislumbrou na Revolução de 1930 a oportunidade de vir a exercer o controle da educação no país" (Saviani, 2006, p. $34)$.

Sendo um plano de educação, tal manifesto abarca as coordenadas para formulação de um sistema nacional de ensino. "O Manifesto é um documento de política educacional em que, mais do que a defesa da Escola Nova, está em causa a defesa da escola pública”. Por isso defende a construção de um sistema nacional de ensino (SAVIANI, 2006, p. 33).

O referido documento aborda que o progresso científico e industrial trouxe inquietações e negação da ordem até então estabelecida, levando o homem a se adaptar às descobertas. Um trecho do Manifesto assim diz: "Falharia o homem à sua missão, se não procurasse tornar-se tão grande quanto a civilização material que chegou a criar" (Manifesto, 1932, p. 11). Foi o próprio desenvolvimento que deu sustentação a esse novo ideário de educação.

Um dos problemas mais graves em termos educacionais que o Manifesto de 1932 aponta se refere à ausência do "nosso aparelho cultural" (p.17), ou seja, não existia um sistema escolar à altura das necessidades do país. Sendo assim, os signatários do movimento escolanovista organizaram por meio do Manifesto uma campanha pela educação nacional.

Neste sentido, as instituições escolares existentes até então já não mais correspondiam às necessidades do século XX, imbuído de descobertas e avanços tecnológicos. Esse documento, considerado público, via a necessidade de uma política 
educacional. Trata-se da união de reformadores em prol de uma bandeira revolucionária, “[...] um programa completo de reconstrução educacional, que será mais cedo mais tarde a tarefa gigantesca das elites coordenadoras das reformas históricas e sociais do povo, no seu período crítico de evolução" (Manifesto, 1932, p. 24).

Segundo Saviani (2008), o Manifesto também é um legado importante deixado pelo século XX. Importante porque influenciou todo o ideário e prática pedagógica no país, estabeleceu novos marcos e valores, consolidando princípios, ideias e realizações, sobretudo no que diz respeito à valorização da atividade espontânea da criança, da satisfação das necessidades individuais e do trabalho em grupo.

Tais aspectos o autor analisa de modo profundo em seu livro História das Ideias Pedagógicas no Brasil, e no livro Escola e Democracia menciona a crítica ao ideário escolanovista, que, embora tenha defendido uma escola acessível a todos por meio de métodos inovadores, não cumpriu essa expectativa e acabou por mudar o foco do ensino do professor e do conteúdo para a criança e suas necessidades; também não se tornou acessível para todos porque não se estendeu a toda a população em idade escolar por falta de estruturas materiais e formativas para isso. Enfim, não resolveu o problema da marginalidade que preconizava (2003).

Para Alves (2001), O movimento escolanovista, que surge como crítica ao ensino vigente, no início do séc. XX, denomina Escola Tradicional a escola burguesa dualista. Este movimento impulsiona para a universalização da educação para todos, se reportando a Comenius com a arte de ensinar tudo a todos, e no século XX a Escola Pública ganha força avassaladora de expansão. Em prol de uma universalização do ensino há um significativo rebaixamento do conteúdo, em substituição dos clássicos pelos manuais didáticos.

A nova concepção de escola que o documento traz é uma reação a toda tendência passiva, intelectualista e verbalista existente na escola chamada tradicional. Defendia "a actividade espontânea, alegre e fecunda, dirigida à satisfação das necessidades do próprio indivíduo" (Manifesto, 1932, p. 54). Surge a preocupação com as necessidades psicobiológicas do indivíduo e a importância do estímulo constante na educação das crianças.

Busca-se portanto, uma "radical transformação da educação pública em todos os seus grãos, tanto à luz do novo conceito de educação, como à vista das necessidades nacionais" (Manifesto, 1932, p. 56). Pode-se afirmar que o século XX foi um período 
marcado também por este documento, cujas ideias já vinham sendo gestadas anteriormente, no século XIX.

\section{Considerações finais}

O Brasil no século $\mathrm{XX}$, em termos educacionais, teve avanços e conquistas significativos, ao analisar-se a história da educação pública brasileira. Entre eles, pode-se citar o aumento do número de escolas e o acesso de um número elevado da população ao ensino público. No entanto, muitas das ideias e reformas propostas no final do século XIX e século XX não se realizaram, devido a vários fatores, como falta de investimentos adequados, falta de continuidade nas propostas, entre outros.

Como esse artigo abordou, o século XX deixou legados positivos e também negativos. Entre os fatores visíveis e de luta ainda hoje, tem-se o desafio da organização de um Sistema Nacional de Educação, para que haja coerência e unificação no todo, bem como a luta pela qualidade da educação nacional. Os fatos mostram que a educação por si só não tem a primazia sobre os problemas sociais, mas a defesa de uma escola pública democrática e de boa qualidade a aqueles que necessitam dela para o acesso ao saber, deve estar sempre à frente, no pensamento e ações dos que pensam e fazem a educação.

\section{REFERÊNCIAS}

ALVES, Gilberto Luiz. A produção da escola pública contemporânea. Campo Grande: Ed. UFMS; Campinas, SP: Autores Associados, 2001.

AMORIM, Hananiel de Souza. A implantação dos grupos escolares no Brasil nas primeiras décadas do século XX. Saberes. Natal, v. 1, n.12, set. 2015, p. 208-224.

CAMBI, Franco. História da pedagogia. Tradução de Álvaro Lorencini. São Paulo: Fundação Editora da UNESP (FEU), 1999.

CANCIAN, Natália. Só 14\% dos adultos brasileiros têm ensino superior, diz relatório da OCDE. Folha de São Paulo, São Paulo, 2016, Caderno de Educação. Disponível em: $<$ http://www1.folha.uol.com.br/educacao/2016/09/1813715-so-14-dos-adultos-brasileirostem-ensino-superior-diz-relatorio-da-ocde.shtml>. Acesso 28 mar. 2018.

MANIFESTO dos Pioneiros da Educação Nova. A Reconstrução Educacional do Brasil. Ao Povo e ao Governo. São Paulo: Companhia Editora Nacional, 1932.

SAVIANI, Dermeval. Escola e democracia: teorias da educação, curvatura da vara, onze teses sobre a educação política. 36. ed. rev. Campinas, SP: Autores Associados, 2003. Coleção Polêmicas do Nosso Tempo. 
SAVIANI, Dermeval et al (Orgs.). O Legado Educacional do Século XX no Brasil. Campinas: Autores Associados, 2004.

SAVIANI, Dermeval. História das idéias pedagógicas no Brasil. Campinas, Autores Associados, 2008.

SILVA, Bruno Adriano R. da. Animador sociocultural: Revista Iberoamericana, v. 2, n. 2, maio/set. 2008.

SOUZA, Rosa Fátima de.; FILHO, Luciano Mendes de Faria. A Contribuição dos Estudos sobre Grupos Escolares para a Renovação da História do Ensino Primário no Brasil. In: VIDAL, Diana Gonçalves (org.). Grupos Escolares: cultura escolar primária e escolarização da infância no Brasil (1893-1971). Campinas, SP: Mercado de Letras, 2006.

VIDAL, Diana Gonçalves. Tecendo História (e recriando memória) da Escola Primária e da Infância no Brasil: os Grupos Escolares em Foco. In: VIDAL, Diana Gonçalves (org.). Grupos Escolares: cultura escolar primária e escolarização da infância no Brasil (18931971). Campinas, SP: Mercado de Letras, 2006.

\section{Como referenciar este artigo}

DARIUS, R. P. P.; DARIUS, F. A. A educação pública no brasil no século xx: considerações à luz da formação dos grupos escolares e do manifesto dos pioneiros da educação nova. Doxa: Rev. Bras. Psico. e Educ., Araraquara, v. 20, n. 1, p. 32-41, jan./jun., 2018. e-ISSN: 2594-8385. DOI: 10.30715/rbpe.v20.n1.2018.11248

Submetido em: 28/03/2018

Aprovado em: 18/05/2018 